\title{
JENIS JENIS LAYANAN BIMBINGAN DAN KONSELING
}

\author{
Nasuha \\ Sekolah Tinggi Agama Islam ( STAI) Darud dakwah Wal-Isyad (DDI) Kota Makassar, \\ Indonesia \\ Email : nasuha2801@gmail.com
}

\begin{abstract}
ABSTRAK
Layanan bimbingan dan konseling merupakan proses pemberian bantuan yang diberikan kepada siswa secara terus menerus agar tercapai kemandirian dalam pemahaman diri, sehingga siswa sanggup mengarahkan dirinya sesuai dengan tuntutan dan keadaan lingkungan sekolah, keluarga dan masyarakat. Dengan adanya bimbingan dan konseling diharapkan dapat memberikan solusi bagi peserta didik di sekolah. Agar peserta didik menjadi lebih baik dari segi perilakunya.Layanan bimbingan dan konseling merupakan bagian integral dari pendidikan di Indonesia dalam upaya membantu siswa agar mencapai perkembangan yang optimal, sesuai dengan potensinya. Oleh karena itu,pelaksanaan bimbingan dan konseling di sekolah menjadi tanggung jawab bersama antara personel sekolah, yaitu kepala sekolah, guru, konselor, dan pengawas.
\end{abstract}

\section{Kata kunci : Jenis jenis Layanan, Bimbingan, Konseling}

\section{PENDAHULUAN}

Dalam Undang-undang Nomor 20 Tahun 2003 Tentang Sistem Pendidikan Nasional, pendidikan diartikan sebagai usaha sadar dan terencana untuk mewujudkan suasana belajar dan proses pembelajaran agar peserta didik secara aktif mengembangkan potensi dirinya untuk memiliki kekuatan spiritual keagamaan, pengendalian diri, kepribadian, kecerdasan akhlak mulia, serta keterampilan yang diperlukan dirinya, masyarakat, bangsa dan negara ${ }^{1}$.

Oleh karena setiap satuan pendidikan harus memberikan layanan yang dapat memfasilitasi perkembangan pribadi siswa secara optimal berupa bimbingan dan konseling. Pemahaman mengenai apa dan bagaimana layanan bimbingan disekolah mutlak diperlukan oleh

\footnotetext{
${ }^{1}$ Undang-Undang Republik Indonesia No.20 Tahun 2003 tentang Sistem
} Pendidikan Nasional.Jakarta:Kementrian Pendidikan Nasional 
pengawas.Sebab adanya layanan bimbingan dan konseling berguna mempermudah dalam mengembangkan potensi diri dalam seseorang.

\section{PEMBAHASAN}

A. Pengertian Layanan Bimbingan dan Konseling

Bimbingan merupakan terjemahan dari guidance yang di dalamnya terkandung beberapa makna. Sertzer \& Stone dalam Winkel (1981 : 66 ) mengemukakan bahwa guidance is the process of helping individuals to understand themselves and their word. Winkel (1981: 65) mengemukakan bahwa guidance mempunyai hubungan dengan guiding : "showing a way" (menunjukkan jalan), leading (memimpin), conducting (menuntun), giving instructions (memberikan petunjuk), regulating (mengatur), governing (mengarahkan) dan giving advice (memberikan nasehat). Bimo ( 2010 : 6 ) mengemukakan bimbingan merupakan suatu pertolongan yang menuntun. Menurut Prayitno dan Erman ( 2004 : 95 ), bimbingan adalah bantuan yang diberikan kepada individu dalam membuat pilihan dan penyesuaian yang bijaksana ${ }^{2}$.

Layanan konseling merupakan salah satu dari Sembilan macam layanan yang ada di dalam program bimbingan dan konseling, layanan konseling merupakan layanan yang memberikan kesempatan kepada siswa untuk mengembangkan dan mengekspresikan diri mereka secara tatap muka dengan guru BK di sekolah, yaitu dengan pengenalan pada diri siswa akan potensi yang mereka miliki disesuaikan dengan kebutuhan, bakat dan minat serta kondisi yang ada di sekolah dan memberikan bantuan kepada siswa atau konseli yang memiliki sebuah permasalahan yang harus diselesaikan ${ }^{3}$.

B. Jenis jenis Layanan Bimbingan dan Konseling

Layanan bimbingan dan konseling memiliki berbagai macam jenis.

Menurut pendapat Prayitno (2004: 254) bahwa ada tujuh jenis layanan bimbingan dan konseling yaitu:

a) Layanan Orientasi

Layanan orientasi merupakan layanan yang memungkinan peserta didik memahami lingkungan baru, terutama lingkungan sekolah dan obyekobyek yang dipelajari, untuk mempermudah dan memperlancar

\footnotetext{
${ }^{2}$ Purnomo, C. (2014). Meningkatkan Pemahaman Studi Lanjut melalui Metode Debat Aktif dalam Layanan Bimbingan Kelompok. Jurnal Pendidikan Penabur, 22(14), 11-16 ${ }^{3}$ Stiyowati, S. (2013). Hubungan Antara Persepsi Siswa Terhadap Pribadi Konselor Dan Fasilitas BK Dengan Minat Siswa Untuk Memanfaatkan Layanan Konseling Di Sekolah. Jurnal BK UNESA, 3(1).
} 
berperannya peserta didik di lingkungan yang baru itu, sekurangkurangnya diberikan dua kali dalam satu tahun yaitu pada setiap awal semester ${ }^{4}$.

b) Layanan Informasi

Layanan informasi adalah layanan yang memungkinan peserta didik menerima dan memahami berbagai informasi (seperti : informasi diri, sosial, belajar, pergaulan, karier, pendidikan lanjutan).

c) Layanan Pembelajaran

Layanan pembelajaran merupakan layanan yang memungkinan peserta didik mengembangkan sikap dan kebiasaan belajar yang baik dalam menguasai materi belajar atau penguasaan kompetensi yang cocok dengan kecepatan dan kemampuan dirinya serta berbagai aspek tujuan dan kegiatan belajar lainnya.

d) Layanan penempatan dan Penyaluran

Layanan penempatan dan penyaluran merupakan layanan yang memungkinan peserta didik memperoleh penempatan dan penyaluran di dalam kelas, kelompok belajar, jurusan/program studi, program latihan, magang, kegiatan ko/ekstra kurikuler sesuai dengan potensi, bakat, minat erta kondisi pribadinya.

e) Layanan Penguasaan Konten

Layanan penguasaan konten merupakan layanan yang membantu peserta didik menguasai konten tertentu, terutama kompetensi dan atau kebiasaan yang berguna dalam kehidupan di sekolah, keluarga, dan masyarakat ${ }^{5}$.

f) Layanan Konseling Perorangan

Layanan konseling perorangan merupakan layanan yang memungkinan peserta didik mendapatkan layanan langsung tatap muka (secara perorangan) dengan guru pembimbing untuk membahas dan mengentaskan permasalahan yang dihadapinya dan perkembangan dirinya 6 .

g) Layanan Bimbingan Kelompok

Layanan bimbingan kelompok merupakan layanan yang memungkinan sejumlah peserta didik secara bersama-sama melalui dinamika kelompok memperoleh bahan dan membahas pokok bahasan (topik) tertentu untuk menunjang pemahaman dan pengembangan kemampuan sosial, baik sebagai individu maupun sebagai pelajar,

\footnotetext{
${ }^{4}$ Awwad, M. (2015). Urgensi layanan bimbingan dan konseling bagi anak berkebutuhan khusus. Al-Tazkiah: Jurnal Bimbingan Dan Konseling Islam, 4(1), 46-64.

${ }^{5}$ Arsi, A., \& Sainuddin, I. H. (2021). Makna Filsafat. 10.31219/osf.io/g8cuk

${ }^{6}$ Sainuddin, I. H. Dakwah di Era Sosial Media. 10.31219/osf.io/g8cuk
} 
kegiatan belajar, karir/jabatan, serta untuk pengambilan keputusan atau tindakan tertentu melalui dinamika kelompok.

\section{PENUTUP}

Layanan bimbingan dan konseling merupakan proses pemberian bantuan yang diberikan kepada siswa secara terus menerus agar tercapai kemandirian dalam pemahaman diri dan siswa dapat mencapai perkembangan yang optimal,sesuai dengan potensinya sehingga siswa sanggup mengarahkan dirinya sesuai dengan tuntutan dan keadaan lingkungan sekolah, keluarga dan masyarakat.Sejalan dengan visi tersebut, maka misi bimbingan dan konseling harus membantu memudahkan siswa mengembangkan seluruh aspek kepribadiannya seoptimal mungkin, sehingga terwujud siswa yang tangguh menghadapi masa kini dan masa mendatang.

Layanan bimbingan dan konseling merupakan bagian yang integral dari keseluruhan proses pendidikan di sekolah. Oleh karena itu, pelaksanaan bimbingan dan konseling di sekolah menjadi tanggung jawab bersama antara personel sekolah, yaitu kepala sekolah, guru, konselor, dan pengawas. Kegiatan bimbingan dan konseling mencakup banyak aspek dan saling kait mengkait,sehingga tidak memungkinkan jika layanan bimbingan dan konseling hanya menjadi tanggung jawab konselor saja. 


\section{DAFTAR PUSTAKA}

Arsi, A., \& Sainuddin, I. H. (2021),Makna Filsafat. 10.31219/osf.io/g8cuk

Awwad, M. (2015). Urgensi layanan bimbingan dan konseling bagi anak berkebutuhan khusus. Al-Tazkiah: Jurnal Bimbingan Dan Konseling Islam, 4(1), 46-64.

Purnomo, C. (2014). Meningkatkan Pemahaman Studi Lanjut melalui Metode Debat Aktif dalam Layanan Bimbingan Kelompok. Jurnal Pendidikan Penabur, 22(14), 1-11.

Sainuddin, I. H. Dakwah di Era Sosial Media. 10.31219/osf.io/g8cuk

Stiyowati, S. (2013). Hubungan Antara Persepsi Siswa Terhadap Pribadi Konselor Dan Fasilitas BK Dengan Minat Siswa Untuk Memanfaatkan Layanan Konseling Di Sekolah. Jurnal BK UNESA, 3(1).

Undang-Undang Republik Indonesia No.20 Tahun 2003 tentang Sistem Pendidikan Nasional.Jakarta:Kementrian Pendidikan Nasional 